\title{
GATA6 loss-of-function mutations contribute to familial dilated cardiomyopathy
}

\author{
LEI XU ${ }^{1 *}$, LAN ZHAO ${ }^{2 *}$, FANG YUAN ${ }^{1}$, WEI-FENG JIANG ${ }^{1}$, HUA LIU $^{1}$, RUO-GU LI ${ }^{1}$, YING-JIA XU ${ }^{1}$, \\ MIN ZHANG ${ }^{1}$, WEI-YI FANG ${ }^{1}$, XIN-KAI QU ${ }^{1}$, YI-QING YANG ${ }^{1,3,4}$ and XING-BIAO QIU ${ }^{1}$ \\ ${ }^{1}$ Department of Cardiology, Shanghai Chest Hospital, Shanghai Jiao Tong University, Shanghai 200030; \\ ${ }^{2}$ Department of Cardiology, Yantaishan Hospital, Yantai, Shandong 264001; ${ }^{3}$ Cardiovascular Research Laboratory, \\ ${ }^{4}$ Central Laboratory, Shanghai Chest Hospital, Shanghai Jiao Tong University, Shanghai 200030, P.R. China
}

Received January 21, 2014; Accepted August 8, 2014

DOI: 10.3892/ijmm.2014.1896

\begin{abstract}
Dilated cardiomyopathy (DCM), the most prevalent form of primary heart muscle disease, is the third most common cause of heart failure and the most frequent reason for cardiac transplantation. Mounting evidence has demonstrated that genetic risk factors are crucial in the pathogenesis of DCM. However, DCM is genetically heterogeneous, and the genetic basis of DCM in a large majority of cases remains unclear. In the current study, the coding exons and flanking introns of the GATA6 gene, which encodes a zinc-finger transcription factor essential for cardiogenesis, was sequenced in 140 unrelated patients with DCM, and two novel heterozygous mutations, p.C447Y and p.H475R, were identified in two index patients with DCM, respectively. Analysis of the pedigrees showed that in each family the mutation co-segregated with DCM transmitted in an autosomal-dominant pattern, with complete penetrance. The missense mutations were absent in 400 control chromosomes and predicted to be disease-causing by MutationTaster or probably damaging by PolyPhen-2. The alignment of multiple GATA6 proteins across species revealed that the altered amino acids were completely conserved evolutionarily. The functional assays showed that the mutated GATA6 proteins were associated with significantly reduced transcriptional activation in comparison with their wild-type counterpart. To the best of our knowledge, this is the first
\end{abstract}

Correspondence to: Dr Xing-Biao Qiu, Department of Cardiology, Shanghai Chest Hospital, Shanghai Jiao Tong University, 241 West Huaihai Road, Shanghai 200030, P.R. China

E-mail: qxingbiao@sina.cn

Dr Yi-Qing Yang, Cardiovascular Research Laboratory, Shanghai Chest Hospital, Shanghai Jiao Tong University, 241 West Huaihai Road, Shanghai 200030, P.R. China

E-mail: yang99yang66@hotmail.com

${ }^{*}$ Contributed equally

Key words: dilated cardiomyopathy, genetics, transcription factor, GATA6, reporter gene analysis study on the association of GATA6 loss-of-function mutations with enhanced susceptibility to familial DCM, which provides novel insight into the molecular mechanism of DCM and suggests potential implications for the antenatal prophylaxis and allele-specific treatment of DCM.

\section{Introduction}

Dilated cardiomyopathy (DCM), which is clinically characterized by progressive cardiac chamber enlargement and contractile dysfunction with normal left ventricular wall thickness, is the most prevalent form of primary myocardial disease, with an estimated prevalence of $1 / 2,500$ in the general population (1). It is the third most common cause of heart failure and the most frequent indication for cardiac transplantation in adults and children (1). The entity of DCM has also been recognized as a major cause of sudden cardiac death, accounting for at least $30 \%$ of the overall mortality in DCM patients (2). The etiologies underlying DCM are diverse, with both environmental and genetic risk factors involved in the pathogenesis of DCM, although most cases remain idiopathic (3). Approximately $25-50 \%$ of DCM individuals had familial forms of the disease, highlighting the important role of genetic defects in the pathogenesis of DCM (4). Pathogenic mutations in $>50$ genes have been associated with various types of DCM, of which autosomal dominant inheritance is the most common type, although other types, including X-linked, autosomal recessive and mitochondrial inheritance, have also been reported (4-8). Nevertheless, the DCM-related genes identified thus far explain only a minority of DCM patients, and the genetic determinants underpinning DCM in a large majority of cases remain elusive.

The GATA transcription factors are a family of zinc finger-containing DNA-binding proteins, which preferentially bind to a 5'-(A/T)GATA(A/G)-3' motif within the regulatory region of target genes (9). Six members of the GATA family have been identified in vertebrates that are parsed into two subfamilies based on their expression profiles. GATA1, GATA 2 and GATA 3 are prominently expressed in hematopoietic cell lineages, while GATA4, GATA5 and GATA6 are broadly expressed in various mesoderm- and endoderm-derived tissues, particularly in the heart (10). GATA4 and GATA6 are 
highly expressed in the embryonic heart and continue the high expression in the post-natal and adult myocardium, where they function as crucial transcriptional regulators of various key cardiac structural and regulatory genes, including the atrial natriuretic factor (ANF), $\alpha$ - and $\beta$-myosin heavy chain, cardiac troponin $\mathrm{C}$, cardiac troponin I, cardiac-restricted ankyrin repeat protein, sodium/calcium exchanger, $\mathrm{A} 1$ adenosine receptor, $\mathrm{m}_{2}$ muscarinic receptor, and the myosin light chain $1 / 3$ genes (10). In mice, the overexpression of GATA4 or GATA6 was sufficient to induce cardiac hypertrophy $(11,12)$, whereas the cardiomyocyte-specific conditional deletion of GATA6 significantly reduced the cardiac hypertrophic response to pressure overload stimulation and rapidly led to heart failure, similar to that observed in the mice with heart-specific deletion of GATA4. Furthermore, the combinatorial deletion of GATA4 and GATA6 from the adult heart resulted in DCM and lethality by 16 weeks of age (12-14). In humans, mutations in GATA4 have been associated with various cardiac phenotypes, including congenital heart diseases, atrial fibrillation and DCM (15-25). Similarly, genetic variations in GATA6 are also involved in the pathogenesis of congenital cardiovascular malformations and atrial fibrillation (26-34), rendering it justifiable to screen GATA6 as a prime candidate gene for DCM.

\section{Materials and methods}

Study participants. A cohort of 140 genetically unrelated patients with DCM was prospectively enlisted from the Han Chinese population. The available relatives of the index patients were also recruited. The controls comprised 200 ethnically matched, unrelated healthy individuals. Prior to enrollment in the study, all the subjects were evaluated for detailed individual and familial histories, underwent complete physical examination, chest radiography, electrocardiogram, echocardiography, and exercise performance testing. Cardiac catheterization, angiography, endomyocardial biopsy, and cardiac magnetic resonance imaging were performed only if there was a strong clinical indication requiring any these procedures. Medical records were reviewed in all cases of deaths thought to be related to DCM. Diagnosis of DCM was made based on the criteria established by the World Health Organization/International Society and Federation of Cardiology Task Force on the Classification of Cardiomyopathy. The criteria included a left ventricular end-diastolic diameter $>27 \mathrm{~mm} / \mathrm{m}^{2}$ and a left ventricular ejection fraction $<40 \%$ or fractional shortening $<25 \%$ in the absence of abnormal loading conditions, coronary artery disease, congenital heart lesions and other systemic diseases $(24,35)$. Exclusion criteria were insufficient echocardiographic image quality, or coexistent conditions that may lead to cardiac contractile dysfunction, such as uncontrolled systemic hypertension, coronary artery or valvular heart disease. A diagnosis of familial DCM was assigned when occurring in at least two closely related family members (36). Individuals were classified as healthy when found to be well with normal echocardiographic parameters. Peripheral venous blood samples from all the participants were collected. The clinical studies were conducted with investigators blinded to the results of genetic testing. The study was performed in accordance with the principles outlined in the 1964 Declaration of Helsinki and its later amendments as well as the ethics laws of China, and the study protocol was approved by the local institutional ethics committee (of Shanghai Chest Hospital, Shanghai Jiao Tong University, Shanghai, China). Written informed consent was obtained from each participant prior to enrollment in the study.

Mutational screening of GATA6. Genomic DNA was extracted from each subject from whole blood leukocytes using a Wizard Genomic DNA Purification kit (Promega, Madison, WI, USA). The coding regions and splice junction sites of GATA6 were sequenced initially in 140 unrelated patients with DCM and subsequently in the available relatives of the index patients carrying the identified mutations and the 200 control individuals using the same method. The referential genomic DNA sequence of GATA6 was derived from GenBank at the National Center for Biotechnology Information (NCBI; accession no. NT_010966; http://www.ncbi.nlm.nih.gov/nucleotide). The primer pairs used to amplify the coding exons and flanking introns of GATA6 by polymerase chain reaction (PCR) were designed as described in a previous study (32). The PCR was performed using HotStar Taq DNA Polymerase (Qiagen GmbH, Hilden, Germany) on a Veriti Thermal Cycler (Applied Biosystems, Foster, CA, USA), with standard conditions and concentrations of reagents. Amplified products were analyzed on $1 \%$ agarose gels stained with ethidium bromide and purified with QIAquick Gel Extraction kit (Qiagen $\mathrm{GmbH}$ ). The two strands of each PCR product were sequenced using a BigDye ${ }^{\circledR}$ Terminator v3.1 Cycle Sequencing kit (Applied Biosystems) on an ABI PRISM 3130 XL DNA Analyzer (Applied Biosystems). The sequencing primers were identical to those designed for the amplification of specific regions of GATA6. The DNA sequences were viewed and assessed using DNA Sequencing Analysis Software v5.1 (Applied Biosystems). A sequence variation was verified by re-sequencing an independent PCR-generated amplicon from the same subject and met our quality control thresholds with a call rate of $>99 \%$. Additionally, for an identified sequence variant, the single nucleotide polymorphism (SNP; http://www.ncbi.nlm.nih. gov/SNP) and human gene mutation (HGM; http://www.hgmd. org) databases were queried to confirm its novelty.

Comparison of amino acid sequences of GATA6 proteins from various species. Amino acid sequences of GATA6 protein from human (NP_005248.2) were aligned with those from rhesus monkey (XP_002800933.1), cattle (XP_002697773.1), mouse (NP_034388.2), rat (NP_062058.1), fowl (NP_990751.1), and zebrafish (NP_571632.1) using the online program of MUSCLE, version 3.6 (http://www.ncbi.nlm.nih.gov).

Prediction of the disease-causing potential of the GATA6 sequence variations. The causative potential of a GATA6 sequence variation was assessed using MutationTaster (an online program at http://www.mutationtaster.org), which provides a probability for the variation to be a pathogenic mutation or a benign polymorphism. The p-value utilized at this point is the probability of the correct prediction as opposed to the probability of error as used in t-test statistics (i.e. a value close to 1 indicates a high 'security' of the prediction). The online program PolyPhen-2 (http://genetics.bwh.harvard.edu/pph2) was also used to assess the pathogenic similarity of an amino acid variation. 
Plasmids and site-directed mutagenesis. The expression vector pcDNA3-hGATA6 used in the present study was generously provided by Dr Angela Edwards-Ghatnekar, from the Division of Rheumatology and Immunology, Medical University of South Carolina (Charleston, SC, USA). The ANF-luciferase reporter plasmid, which contains the 2600-bp 5'-flanking region of the ANF gene, i.e., ANF(-2600)-Luc, was kindly provided by Dr Ichiro Shiojima, from the Department of Cardiovascular Science and Medicine, Chiba University Graduate School of Medicine (Chuo-ku, Chiba, Japan). Each identified mutation was introduced into the plasmid containing the wild-type human GATA6 cDNA to generate the mutant expression vector using a QuickChange II XL Site-Directed Mutagenesis kit (Stratagene, La Jolla, CA, USA) with a complementary pair of primers, which was verified by direct sequencing.

Dual-luciferase reporter assay. HEK-293 cells plated onto 12 -well plates at an initial density of $2 \times 10^{4}$ cells/well were cultured in Dulbecco's modified Eagle's medium supplemented with $10 \%$ fetal bovine serum and $1 \%$ penicillin/streptomycin at $37^{\circ} \mathrm{C}$ with $5 \% \mathrm{CO}_{2}$, and grown to a confluence of $\sim 80 \%$. Transient transfection was subsequently performed using Lipofectamine ${ }^{\circledR} 2000$ Transfection Reagent (Invitrogen Life Technologies, Carlsbad, CA, USA) in accordance with the manufacturer's instructions. The ANF(-2600)-Luc reporter vector and an internal control reporter plasmid pGL4.75 (hRluc/ $\mathrm{CMV}$; Promega) were used in transfection assays to evaluate the transcriptional activation function of the GATA6 mutants. HEK-293 cells were transfected with $0.4 \mu \mathrm{g}$ of empty vector pcDNA3, or $0.4 \mu \mathrm{g}$ of wild-type or mutant pcDNA3-hGATA6 expression plasmid, together with $0.4 \mu \mathrm{g}$ of $\mathrm{ANF}(-2600)-\mathrm{Luc}$ reporter construct and $0.04 \mu \mathrm{g}$ of pGL4.75 control reporter vector. For the co-transfection experiments, $0.2 \mu \mathrm{g}$ of wild-type pcDNA3-hGATA6, $0.2 \mu \mathrm{g}$ of mutant pcDNA3-hGATA6, $0.4 \mu \mathrm{g}$ of ANF(-2600)-Luc, and $0.04 \mu \mathrm{g}$ of pGL4.75 were used. Firefly luciferase and Renilla luciferase activities were measured with the Dual-Glo luciferase assay system (Promega) $48 \mathrm{~h}$ after transfection and normalized to the cells transfected with empty vector. The activity of the $A N F$ promoter was presented as the fold activation of normalized Firefly luciferase relative to normalized Renilla luciferase. Three independent experiments were performed at minimum for wild-type and mutant GATA6. Experiments were performed in triplicate

Statistical analysis. Data are expressed as means \pm SD. Continuous variables were tested for normality of distribution, and the Student's unpaired t-test was used for comparison of numeric variables between two groups. Comparison of the categorical variables between two groups was performed using Pearson's $\chi^{2}$ test or Fisher's exact test when appropriate. A two-tailed $\mathrm{p}<0.05$ was considered to indicate a statistically significant result.

\section{Results}

Clinical characteristics of the study population. A cohort of 140 genetically unrelated patients with DCM (76 males, mean age $53.2 \pm 12.8$ years) was clinically evaluated in contrast to a total of 200 ethnically matched, unrelated healthy indi-
Table I. Baseline clinical characteristics of the study subjects.

\begin{tabular}{lcc}
\hline Variables & Patients $(\mathrm{n}=140)$ & Controls $(\mathrm{n}=200)$ \\
\hline Age (years) & $53.2 \pm 12.8$ & $54.6 \pm 10.7$ \\
Male (\%) & $76(54.3)$ & $105(52.5)$ \\
Family history & $51(36.4)^{\mathrm{a}}$ & $0(0)$ \\
of DCM (\%) & & \\
SBP (mmHg) & $115.8 \pm 14.6^{\mathrm{a}}$ & $126.2 \pm 11.5$ \\
DBP (mmHg) & $75.2 \pm 8.7^{\mathrm{a}}$ & $82.5 \pm 7.3$ \\
HR (bpm) & $92.6 \pm 10.1^{\mathrm{a}}$ & $75.8 \pm 9.6$ \\
LVEDD (mm) & $62.1 \pm 8.5^{\mathrm{a}}$ & $48.1 \pm 6.2$ \\
LVESD (mm) & $51.5 \pm 7.2^{\mathrm{a}}$ & $32.7 \pm 6.0$ \\
LVEF (\%) & $38.9 \pm 5.3^{\mathrm{a}}$ & $64.2 \pm 6.5$ \\
NYHA function & & \\
class (\%) & & \\
I & $25(17.9)$ & NA \\
II & $47(33.6)$ & NA \\
III & $52(37.1)$ & NA \\
IV & $16(11.4)$ & NA \\
\end{tabular}

DCM, dilated cardiomyopathy; SBP, systolic blood pressure; DBP, diastolic blood pressure; HR, heart rate; LVEDD, left ventricular end-diastolic diameter; LVESD, left ventricular end-systolic diameter; LVEF, left ventricular ejection fraction; NYHA, New York Heart Association; NA, not applicable or not available. ${ }^{\mathrm{a}} \mathrm{P}<0.0001$ when compared with the controls.

viduals (105 males, mean age 54.6 \pm 10.7 years) that were used as controls. Of the 140 DCM patients, 51 had a positive family history of DCM, while no family history of DCM was confirmed in the 200 control individuals. Compared with those in the control group, blood pressure and left ventricular ejection fraction were statistically decreased whereas the heart rate, left ventricular end-diastolic diameter and left ventricular end-systolic diameter were significantly increased in the patient group. The baseline clinical characteristics of the 140 unrelated DCM patients are shown in Table I.

Identification of GATA6 mutations in DCM patients. By analysis of the protein coding sequence of GATA6 in the 140 unrelated DCM patients, two heterozygous missense mutations were identified in 2 of 140 patients, respectively, with a mutational prevalence of $\sim 1.43 \%$. Specifically, a substitution of adenine for guanine in the second nucleotide of codon 447 of the GATA6 gene (c.1340G>A), equivalent to the transition of cysteine to tyrosine at amino acid position 447 (p.C447Y), was identified in the proband from family 1 . A transversion of adenine into guanine at coding nucleotide 1424 (c.1424A>G), predicting the change of histidine into arginine at amino acid 475 (p.H475R), was identified in the index patient from family 2 . The sequence chromatograms showing the detected heterozygous GATA6 variations in contrast to the corresponding control sequences are shown in Fig. 1. A schematic diagram of GATA6 showing the structural domains and the locations of the identified mutations is presented in Fig. 2. The 


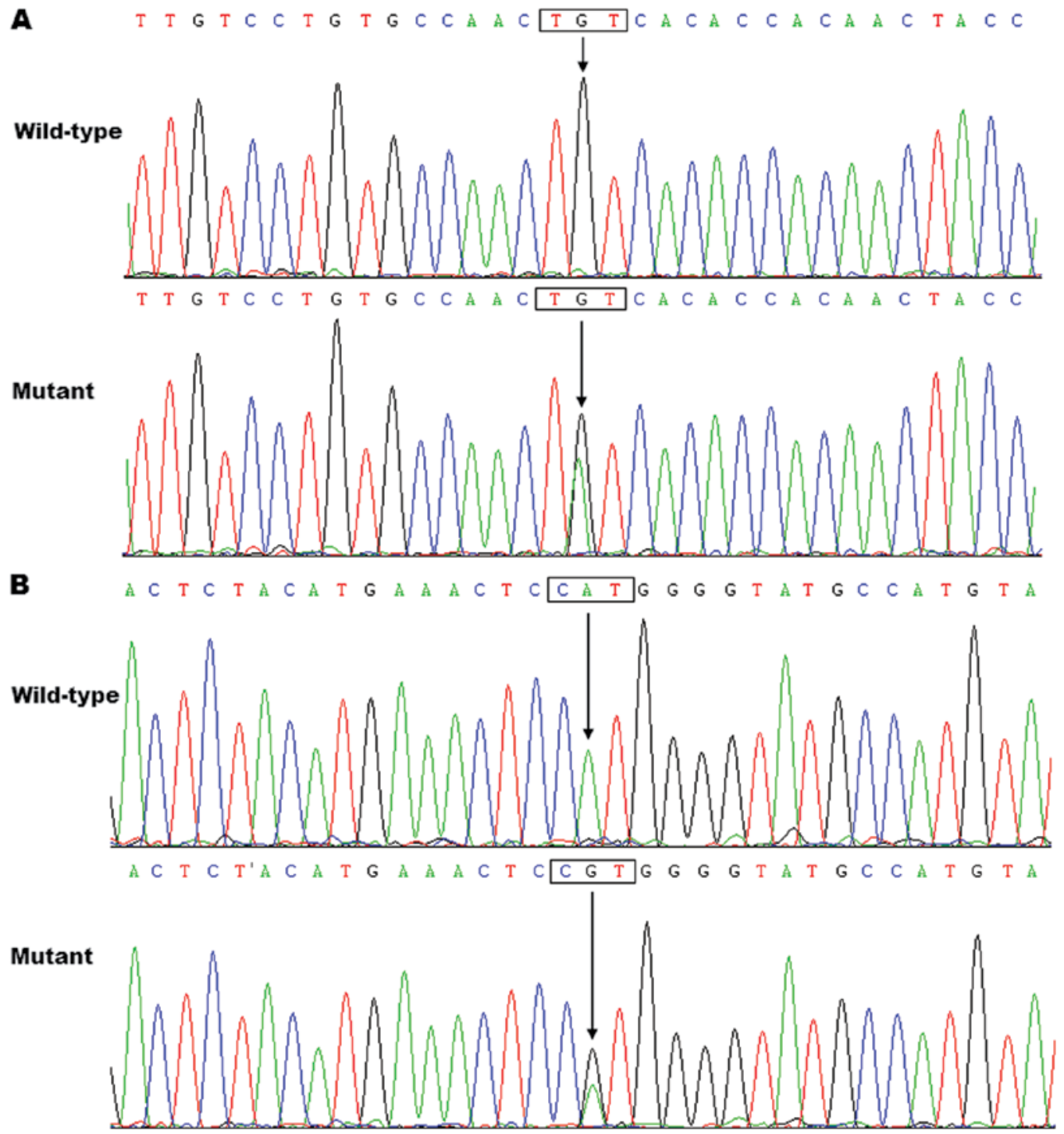

Figure 1. Sequence electropherograms showing the GATA6 mutations in contrast to their corresponding controls. The arrow indicates the heterozygous nucleotides of G/A in the probands from families (A) 1 and (B) 2, respectively, (mutant) or the homozygous nucleotides of (A) G/G and (B) A/A in the corresponding control individuals (wild-type). The rectangle denotes the nucleotides constituting a codon of GATA6.

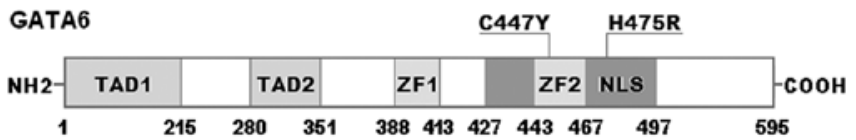

Figure 2. Schematic diagram showing GATA6 protein structures with the dilated cardiomyopathy (DCM)-related mutations indicated. The mutations identified in patients with familial DCM are shown above the structural domains. NH2, amino-terminus; TAD, transcriptional activation domain $\mathrm{ZF}$, zinc finger; NLS, nuclear localization signal; $\mathrm{COOH}$, carboxyl-terminus.

two variants were not observed in 400 control alleles or identified in the SNP and HGM databases, which were consulted again on January 21, 2014.

A genetic screen of family members of the mutation carriers demonstrated that in each family, the variation was present in all the affected family members available, but absent in the unaffected family members examined. Analysis of the pedigrees showed that in each family the variation co-segregated with DCM transmitted in an autosomal dominant pattern with complete penetrance. The pedigree structures of the two families are shown in Fig. 3. In family 1, the proband's father (I-1) and two brothers (II-3 and II-8) also had an electrocardiogram documented atrial fibrillation. The phenotypic characteristics and results of genetic screening of the affected pedigree members are shown in Table II.

Multiple alignments of GATA6 protein sequences among various species. A cross-species alignment of multiple GATA6 protein sequences showed that the affected amino acids were highly conserved from human to zebrafish, indicating that these amino acids are functionally important (Fig. 4).

Disease-causing potential of GATA6 sequence variations. The GATA6 sequence variations of c. $1340 \mathrm{G}>\mathrm{A}$ and c. $1424 \mathrm{~A}>\mathrm{G}$ were predicted to be disease-causing, with an identical p-value of 1.00000. No SNPs in the altered regions were identified in the MutationTaster database. The amino acid substitutions 
Table II. Phenotypic characteristics and status of GATA6 mutations of the affected pedigree members.

\begin{tabular}{|c|c|c|c|c|c|c|c|}
\hline \multicolumn{2}{|c|}{ Subject information } & \multirow[b]{2}{*}{$\begin{array}{c}\text { Age } \\
\text { (years) }\end{array}$} & \multirow{2}{*}{ 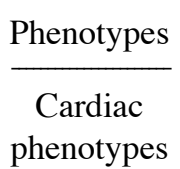 } & \multicolumn{2}{|c|}{ Echocardiogram } & \multirow[b]{2}{*}{$\begin{array}{l}\text { LVEF } \\
(\%)\end{array}$} & \multirow{2}{*}{ 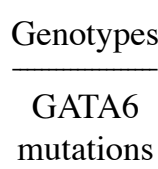 } \\
\hline Identity & Gender & & & $\begin{array}{l}\text { LVEDD } \\
(\mathrm{nm})\end{array}$ & $\begin{array}{l}\text { LVESD } \\
(\mathrm{nm})\end{array}$ & & \\
\hline Family 1 & & & & & & & $\mathrm{C} 447 \mathrm{Y}$ \\
\hline $\mathrm{I}-1$ & M & $60^{\mathrm{a}}$ & $\mathrm{DCM}, \mathrm{AF}$ & NA & NA & NA & NA \\
\hline II-1 & M & $21^{\mathrm{a}}$ & DCM & NA & NA & NA & NA \\
\hline II-3 & $\mathrm{F}$ & $53^{\mathrm{a}}$ & $\mathrm{DCM}, \mathrm{AF}$ & NA & NA & NA & NA \\
\hline II-5 & $\mathrm{F}$ & 55 & DCM & 74 & 66 & 28 & $+1-$ \\
\hline II-8 & M & 50 & $\mathrm{DCM}, \mathrm{AF}$ & 60 & 48 & 35 & $+1-$ \\
\hline III-1 & M & 29 & DCM & 52 & 37 & 45 & $+1-$ \\
\hline Family 2 & & & & & & & H475R \\
\hline $\mathrm{I}-1$ & $\mathrm{M}$ & $62^{\mathrm{a}}$ & DCM & NA & NA & NA & NA \\
\hline II-1 & M & 58 & DCM & 68 & 58 & 37 & $+1-$ \\
\hline II-4 & $\mathrm{F}$ & 55 & DCM & 56 & 44 & 40 & $+1-$ \\
\hline III-1 & M & 32 & $\mathrm{DCM}$ & 47 & 36 & 46 & $+1-$ \\
\hline
\end{tabular}

${ }^{\mathrm{a} A g e}$ at death. M, male; F, female; DCM, dilated cardiomyopathy; AF, atrial fibrillation; LVEDD, left ventricular end-diastolic diameter; LVESD, left ventricular end-systolic diameter; LVEF, left ventricular ejection fraction; +, presence of a mutant allele; -, absence of a mutant allele; NA, not available or not applicable.

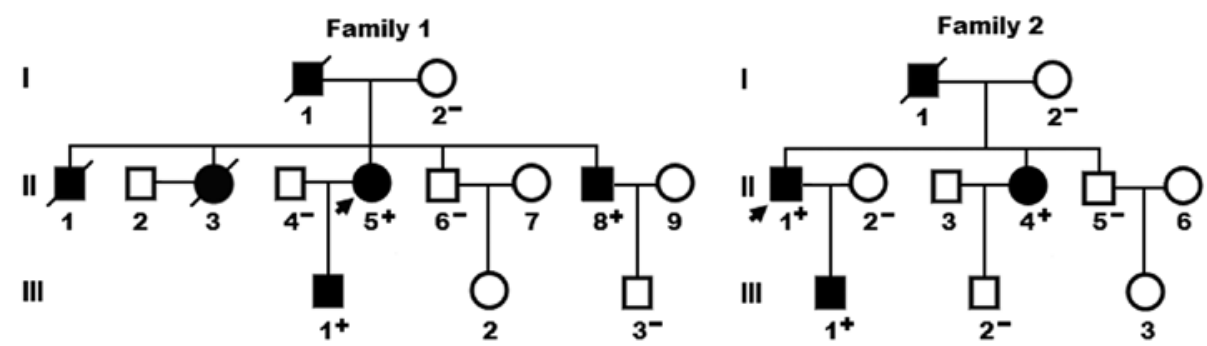

Figure 3. Pedigree structures of the families with dilated cardiomyopathy (DCM). Families are designated as family 1 and family 2 , respectively. Family members are identified by generations and numbers. Square, male family member; circle, female member; solid symbol, affected member; open symbol, unaffected member; symbol with a slash, dead member; arrow, proband; '+', presence of a heterozygous mutation; '-', absence of a heterozygous mutation.

of $\mathrm{C} 447 \mathrm{Y}$ and H475R in GATA6 were also predicted by PolyPhen-2 to be damaging, with scores of 1.000 (sensitivity 0.00 ; specificity 1.00 ) for p.C447Y and 0.972 (sensitivity 0.77 ; specificity 0.96 ) for p.H475R, respectively.

Reduced transcriptional activity of the GATA6 mutants. The wild-type GATA6, C447Y-mutant GATA6 and H475R-mutant GATA6 activated the ANF promoter by $\sim 12-, \sim 2$ - and $\sim 3$-fold, respectively. When wild-type GATA6 was co-expressed with the same amount of C447Y-mutant GATA6 or H475Rmutant GATA6, the induced activation of the ANF promoter was the same as $\sim 6$-fold. These results showed that the two GATA6 mutants are associated with significantly reduced transcriptional activity compared with their wild-type counterpart (Fig. 5).

\section{Discussion}

In the current study, two novel heterozygous GATA6 mutations, p.C447Y and p.H475R, were identified in two families with DCM. In each family the mutation co-segregated with DCM transmitted in an autosomal dominant mode with complete penetrance. The two mutations, which were absent in 400 referential chromosomes from an ethnically matched control population, altered the amino acids that were completely conserved evolutionarily and were predicted to be pathogenic. Functional assays showed that the mutant GATA6 proteins were associated with significantly reduced transcriptional activity. Therefore, it is likely that functionally compromised GATA6 contribute to DCM in these families.

Human GATA6 gene maps to chromosome 18q11.1q11.2, coding for a protein with 595 amino acids (37). The functional domains of GATA6 comprise two transcriptional activation domains (TAD1, amino acids 1-215; TAD2, amino acids 280-351), two adjacent zinc fingers (ZF1, amino acids 388-413; ZF2, amino acids 443-467), and one nuclear localization signal (NLS, amino acids 427-497). The two TADs are important for the appropriate transcriptional activity of GATA6. The N-terminal ZF2 is responsible for DNA sequence recognition and binding to the consensus motif, while the 


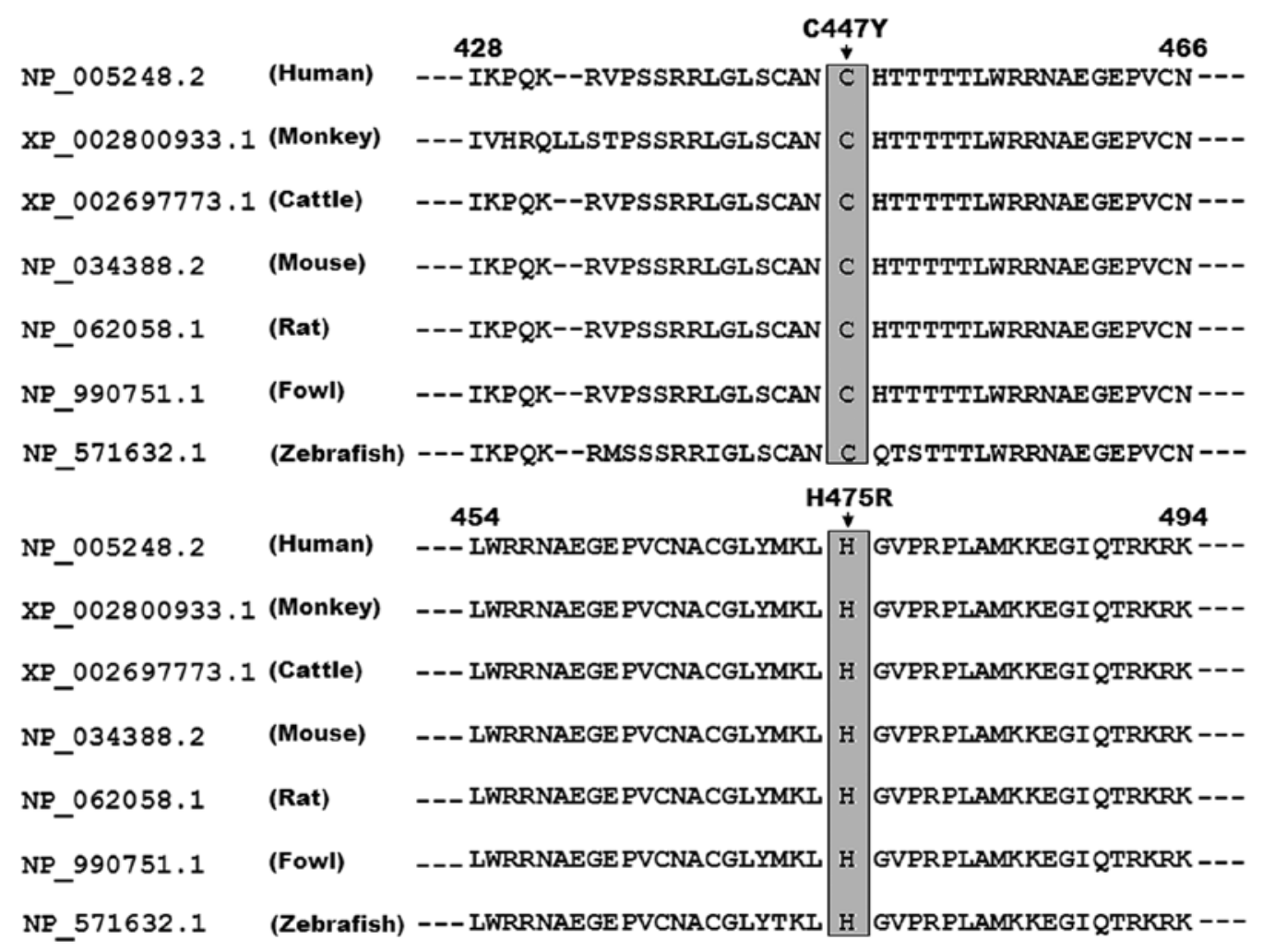

Figure 4. Multiple alignments of GATA6 protein sequences across species. The altered amino acids of p.C447 and p.H475 are completely conserved evolutionarily among various species.

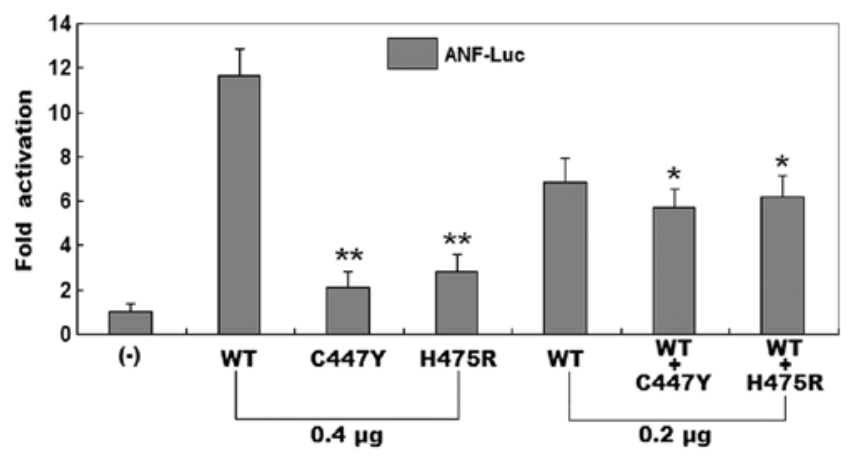

Figure 5. Functional defects caused by GATA6 mutations. Activation of atrial natriuretic factor (ANF)-luciferase reporter in HEK-293 cells by GATA6 wild-type (WT), mutant C447Y or mutant H475R, alone or in combination, revealed significantly reduced transcriptional activation by mutant proteins Experiments were performed in triplicate, and mean \pm standard deviations are given. ${ }^{* *} \mathrm{P}<0.001$ and ${ }^{*} \mathrm{P}<0.005$ when compared with wild-type GATA6.

C-terminal ZF1 is crucial for the sequence specificity and stability of protein-DNA binding. The NLS is required for the sub-cellular trafficking and distribution of GATA6 (33). The GATA6 mutations p.C447Y and p.H475R identified in the present study are located in ZF2 and NLS, respectively, and may therefore exert impact on the transcriptional activity of GATA6 by interfering with the binding to target DNA or nuclear distribution of GATA6.

GATA6 has been found to mediate the expression of several target genes during embryogenesis and cardiac morphogenesis, including the genes that encode atrial natriuretic factor (ANF), brain natriuretic peptide, $\alpha$ - and $\beta$-myosin heavy chain, and gap junction protein $\mathrm{Cx} 40(10,38)$. Thus, the functional effect of the GATA6 mutation may be investigated by assay of the transcriptional activity of a target gene promoter in tool cells. In the present study, the functional characteristics of the novel GATA6 mutations identified in the DCM patients were determined by transcriptional activation analysis and the results showed a significantly decreased transcriptional activity on the downstream gene, $A N F$. These findings suggest that haploinsufficiency or a dominant-negative effect resulting from GATA6 loss-of-function mutation is potentially an alternative molecular mechanism underpinning DCM.

Association of genetically defective GATA6 with increased vulnerability to DCM has been established in animals. In zebrafish, embryos depleted of GATA6 developed variable cardiac morphogenetic defects including cardia bifida, partially fused tube, and fused but non-looping tube (39). By contrast, zebrafish embryos depleted of GATA4 and GATA6 were heartless and restoring either gene product was sufficient to rescue cardiomyocyte specification (40). In mice, among the mammalian GATA factors that have been identified thus far (GATA1-GATA6), GATA6 was the earliest expressed during embryonic development, and GATA6-deficient embryos died shortly after implantation (41). Although the mice heterozygous for a GATA4 or GATA6 null allele were normal, compound heterozygosity of GATA4 and GATA6 resulted in embryonic lethality accompanied by a spectrum of cardiovascular defects, including thin-walled myocardium, ventricular septal defect, persistent truncus arteriosis, double outlet right ventricle, myocardial hypoplasia, reduced prolife- 
ration of cardiomyocytes, and the impaired differentiation of vascular smooth muscle cells $(42,43)$. The mice with a cardiomyocyte-specific conditional deletion of GATA6, which lacked $>95 \%$ of GATA6 protein in the heart, were viable and survived into adulthood, but they were predisposed to progressive deterioration in cardiac function and enlargement of heart in adulthood, a phenotype similar to that of GATA4 heart-specific deleted mice. Furthermore, the combinatorial deletion of GATA4 and GATA6 from the adult murine heart led to DCM (12). By contrast, the overexpression of GATA6 was sufficient to induce myocardial hypertrophy in vitro and in vivo, both alone and in combination with GATA4 $(11,12)$. These experimental results emphasize the pivotal role of GATA6 in the development and remodeling of the heart.

GATA6 has been confirmed to regulate the expression of multiple key cardiac genes alone or in cooperation with its transcriptionally synergistic partners, such as GATA4, NKX2-5 and TBX20, and in humans, an increasing number of mutations in such target molecules as $\alpha$-actin, $\alpha$-myosin heavy chain, troponin $\mathrm{C}$, and troponin I, as well as in the transcriptional cooperative partners of GATA6, including GATA4, NKX2-5 and TBX20, are involved in the pathogenesis of DCM $(10,24,25,44,45)$. These findings suggest that functionally compromised GATA6 predisposes to DCM probably by reducing the expression of genes essential for cardiac structure and function.

Atrial fibrillation was documented in three DCM patients from family 1 , consistent with previous studies on the association of GATA6 mutations with atrial fibrillation (32-34). Similarly, mutations in other cardiac transcriptional factor genes, such as GATA4, GATA5, NKX2-5 and PITX2c, were also associated with atrial fibrillation (21-23,46-53). These observations support the hypothesis that a subset of atrial fibrillation may have developmental origin.

In conclusion, to the best of our knowledge, this is the first study to connect GATA6 loss-of-function mutations with enhanced susceptibility to DCM, providing novel insight into the molecular mechanism of DCM, suggesting potential implications for the antenatal prophylaxis and allele-specific treatment of DCM.

\section{Acknowledgements}

We are grateful to the participants for their dedication to the study. This study was supported by a grant from the National Natural Science Fund of China (no. 81270161) and a grant from the Natural Science Fund of Shanghai, China (no. 14ZR1438000).

\section{References}

1. Maron BJ, Towbin JA, Thiene G, Antzelevitch C, Corrado D, Arnett D, Moss AJ, Seidman CE and Young JB; American Heart Association; Council on Clinical Cardiology, Heart Failure and Transplantation Committee; Quality of Care and Outcomes Research and Functional Genomics and Translational Biology Interdisciplinary Working Groups; Council on Epidemiology and Prevention: Contemporary definitions and classification of the cardiomyopathies: an American Heart Association Scientific Statement from the Council on Clinical Cardiology, Heart Failure and Transplantation Committee; Quality of Care and Outcomes Research and Functional Genomics and Translational Biology Interdisciplinary Working Groups; and Council on Epidemiology and Prevention. Circulation 113: 1807-1816, 2006.
2. Sen-Chowdhry S and McKenna WJ: Sudden death from genetic and acquired cardiomyopathies. Circulation 125: 1563-1576, 2012.

3. Towbin JA, Lowe AM, Colan SD, Sleeper LA, Orav EJ, Clunie S, Messere J, Cox GF, Lurie PR, Hsu D, Canter C, Wilkinson JD and Lipshultz SE: Incidence, causes, and outcomes of dilated cardiomyopathy in children. JAMA 296: 1867-1876, 2006.

4. McNally EM, Golbus JR and Puckelwartz MJ: Genetic mutations and mechanisms in dilated cardiomyopathy. J Clin Invest 123: 19-26, 2013.

5. Refaat MM, Lubitz SA, Makino S, Islam Z, Frangiskakis JM, Mehdi H, Gutmann R, Zhang ML, Bloom HL, MacRae CA, Dudley SC, Shalaby AA, Weiss R, McNamara DM, London B and Ellinor PT: Genetic variation in the alternative splicing regulator RBM20 is associated with dilated cardiomyopathy. Heart Rhythm 9: 390-396, 2012.

6. Disertori M, Quintarelli S, Grasso M, Pilotto A, Narula N, Favalli V, Canclini C, Diegoli M, Mazzola S, Marini M, Del Greco M, Bonmassari R, Masè M, Ravelli F, Specchia C and Arbustini E: Autosomal recessive atrial dilated cardiomyopathy with standstill evolution associated with mutation of Natriuretic Peptide Precursor A. Circ Cardiovasc Genet 6: 27-36, 2013.

7. Paavola J, Schliffke S, Rossetti S, Kuo IY, Yuan S, Sun Z, Harris PC, Torres VE and Ehrlich BE: Polycystin-2 mutations lead to impaired calcium cycling in the heart and predispose to dilated cardiomyopathy. J Mol Cell Cardiol 58: 199-208, 2013.

8. Wahbi K, Béhin A, Bécane HM, Leturcq F, Cossée M, Laforêt P, Stojkovic T, Carlier P, Toussaint M, Gaxotte V, Cluzel P, Eymard B and Duboc D: Dilated cardiomyopathy in patients with mutations in anoctamin 5. Int J Cardiol 168: 76-79, 2013.

9. Oka T, Xu J and Molkentin JD: Re-employment of developmental transcription factors in adult heart disease. Semin Cell Dev Biol 18: 117-131, 2007.

10. Molkentin JD: The zinc finger-containing transcription factors GATA-4, -5 , and -6 . Ubiquitously expressed regulators of tissue-specific gene expression. J Biol Chem 275: 38949-38952, 2000.

11. Liang Q, De Windt LJ, Witt SA, Kimball TR, Markham BE and Molkentin JD: The transcription factors GATA4 and GATA6 regulate cardiomyocyte hypertrophy in vitro and in vivo. J Biol Chem 276: 30245-30253, 2001.

12. van Berlo JH, Elrod JW, van den Hoogenhof MM, York AJ, Aronow BJ, Duncan SA and Molkentin JD: The transcription factor GATA-6 regulates pathological cardiac hypertrophy. Circ Res 107: 1032-1040, 2010.

13. Bisping E, Ikeda S, Kong SW, Tarnavski O, Bodyak N, McMullen JR, Rajagopal S, Son JK, Ma Q, Springer Z, Kang PM, Izumo $\mathrm{S}$ and $\mathrm{Pu}$ WT: Gata4 is required for maintenance of postnatal cardiac function and protection from pressure overloadinduced heart failure. Proc Natl Acad Sci USA 103: 14471-14476, 2006.

14. Oka T, Maillet M, Watt AJ, Schwartz RJ, Aronow BJ, Duncan SA and Molkentin JD: Cardiac-specific deletion of Gata4 reveals its requirement for hypertrophy, compensation, and myocyte viability. Circ Res 98: 837-845, 2006.

15. Garg V, Kathiriya IS, Barnes R, Schluterman MK, King IN, Butler CA, Rothrock CR, Eapen RS, Hirayama-Yamada K, Joo K, Matsuoka R, Cohen JC and Srivastava D: GATA4 mutations cause human congenital heart defects and reveal an interaction with TBX5. Nature 424: 443-447, 2003.

16. Rajagopal SK, Ma Q, Obler D, Shen J, Manichaikul A, Tomita-Mitchell A, Boardman K, Briggs C, Garg V, Srivastava D, Goldmuntz E, Broman KW, Benson DW, Smoot LB and Pu WT: Spectrum of heart disease associated with murine and human GATA4 mutation. J Mol Cell Cardiol 43: 677-685, 2007.

17. Wang J, Fang M, Liu XY, Xin YF, Liu ZM, Chen XZ, Wang XZ, Fang WY, Liu X and Yang YQ: A novel GATA4 mutation responsible for congenital ventricular septal defects. Int J Mol Med 28: 557-564, 2011.

18. Liu XY, Wang J, Zheng JH, Bai K, Liu ZM, Wang XZ, Liu X, Fang WY and Yang YQ: Involvement of a novel GATA4 mutation in atrial septal defects. Int J Mol Med 28: 17-23, 2011.

19. McCulley DJ and Black BL: Transcription factor pathways and congenital heart disease. Curr Top Dev Biol 100: 253-277, 2012.

20. Yang YQ, Gharibeh L, Li RG, Xin YF, Wang J, Liu ZM, Qiu XB, Xu YJ, Xu L, Qu XK, Liu X, Fang WY, Huang RT, Xue S and Nemer G: GATA4 loss-of-function mutations underlie familial tetralogy of Fallot. Hum Mutat 34: 1662-1671, 2013. 
21. Posch MG, Boldt LH, Polotzki M, Richter S, Rolf S, Perrot A, Dietz R, Ozcelik C and Haverkamp W: Mutations in the cardiac transcription factor GATA4 in patients with lone atrial fibrillation. Eur J Med Genet 53: 201-203, 2010.

22. Jiang JQ, Shen FF, Fang WY, Liu X and Yang YQ: Novel GATA4 mutations in lone atrial fibrillation. Int J Mol Med 28: 1025-1032, 2011.

23. Wang J, Sun YM and Yang YQ: Mutation spectrum of the GATA4 gene in patients with idiopathic atrial fibrillation. Mol Biol Rep 39: 8127-8135, 2012.

24. Li RG, Li L, Qiu XB, Yuan F, Xu L, Li X, Xu YJ, Jiang WF, Jiang JQ, Liu X, Fang WY, Zhang M, Peng LY, Qu XK and Yang YQ: GATA4 loss-of-function mutation underlies familial dilated cardiomyopathy. Biochem Biophys Res Commun 439: 591-596, 2013.

25. Zhao L, Xu JH, Xu WJ, Yu H, Wang Q, Zheng HZ, Jiang WF, Jiang JF and Yang YQ: A novel GATA4 loss-of-function mutation responsible for familial dilated cardiomyopathy. Int J Mol Med 33: 654-660, 2014.

26. Kodo K, Nishizawa T, Furutani M, Arai S, Yamamura E, Joo K, Takahashi T, Matsuoka R and Yamagishi H: GATA6 mutations cause human cardiac outflow tract defects by disrupting semaphorin-plexin signaling. Proc Natl Acad Sci USA 106 13933-13938, 2009

27. Lin X, Huo Z, Liu X, Zhang Y, Li L, Zhao H, Yan B, Liu Y, Yang Y and Chen YH: A novel GATA6 mutation in patients with tetralogy of Fallot or atrial septal defect. J Hum Genet 55: 662-667, 2010

28. Maitra M, Koenig SN, Srivastava D and Garg V: Identification of GATA6 sequence variants in patients with congenital heart defects. Pediatr Res 68: 281-285, 2010.

29. Wang J, Luo XJ, Xin YF, Liu Y, Liu ZM, Wang Q, Li RG, Fang WY, Wang XZ and Yang YQ: Novel GATA6 mutations associated with congenital ventricular septal defect or tetralogy of fallot. DNA Cell Biol 31: 1610-1617, 2012.

30. Zheng GF, Wei D, Zhao H, Zhou N, Yang YQ and Liu XY: A novel GATA6 mutation associated with congenital ventricular septal defect. Int J Mol Med 29: 1065-1071, 2012.

31. Huang RT, Xue S, Xu YJ and Yang YQ: Somatic mutations in the GATA6 gene underlie sporadic tetralogy of Fallot. Int J Mol Med 31: 51-58, 2013

32. Yang YQ, Wang XH, Tan HW, Jiang WF, Fang WY and Liu X: Prevalence and spectrum of GATA6 mutations associated with familial atrial fibrillation. Int J Cardiol 155: 494-496, 2012.

33. Li J, Liu WD, Yang ZL and Yang YQ: Novel GATA6 loss-of-function mutation responsible for familial atrial fibrillation. Int J Mol Med 30: 783-790, 2012.

34. Yang YQ, Li L, Wang J, Zhang XL, Li RG, Xu YJ, Tan HW, Wang XH, Jiang JQ, Fang WY and Liu X: GATA6 loss-of-function mutation in atrial fibrillation. Eur J Med Genet 55: 520-526, 2012

35. Elliott P, O'Mahony C, Syrris P, Evans A, Rivera Sorensen C, Sheppard MN, Carr-White G, Pantazis A and McKenna WJ Prevalence of desmosomal protein gene mutations in patients with dilated cardiomyopathy. Circ Cardiovasc Genet 3: 314-322, 2010.

36. Mestroni L, Rocco C, Gregori D, Sinagra G, Di Lenarda A, Miocic S, Vatta M, Pinamonti B, Muntoni F, Caforio AL, McKenna WJ, Falaschi A, Giacca M and Camerini: Familial dilated cardiomyopathy: evidence for genetic and phenotypic heterogeneity. Heart Muscle Disease Study Group. J Am Coll Cardiol 34: 181-190, 1999.

37. Suzuki E, Evans T, Lowry J, Truong L, Bell DW, Testa JR and Walsh K: The human GATA-6 gene: structure, chromosomal location, and regulation of expression by tissue-specific and mitogen-responsive signals. Genomics 38: 283-290, 1996.
38. Rémond MC, Iaffaldano G, O'Quinn MP, Mezentseva NV, Garcia V, Harris BS, Gourdie RG, Eisenberg CA and Eisenberg LM: GATA6 reporter gene reveals myocardial phenotypic heterogeneity that is related to variations in gap junction coupling. Am J Physiol Heart Circ Physiol 301: H1952-H1964, 2011.

39. Peterkin T, Gibson A and Patient R: GATA-6 maintains BMP-4 and $\mathrm{Nkx} 2$ expression during cardiomyocyte precursor maturation. EMBO J 22: 4260-4273, 2003.

40. Holtzinger A and Evans T: Gata5 and Gata6 are functionally redundant in zebrafish for specification of cardiomyocytes. Dev Biol 312: 613-622, 2007.

41. Koutsourakis M, Langeveld A, Patient R, Beddington R and Grosveld F: The transcription factor GATA6 is essential for early extraembryonic development. Development 126: 723-732, 1999.

42. Xin M, Davis CA, Molkentin JD, Lien CL, Duncan SA, Richardson JA and Olson EN: A threshold of GATA4 and GATA6 expression is required for cardiovascular development. Proc Natl Acad Sci USA 103: 11189-11194, 2006.

43. Zhao R, Watt AJ, Battle MA, Li J, Bondow BJ and Duncan SA: Loss of both GATA4 and GATA6 blocks cardiac myocyte differentiation and results in acardia in mice. Dev Biol 317: 614-619, 2008.

44. Costa MW, Guo G, Wolstein O, Vale M, Castro ML, Wang L, Otway R, Riek P, Cochrane N, Furtado M, Semsarian C, Weintraub RG, Yeoh T, Hayward C, Keogh A, Macdonald P, Feneley M, Graham RM, Seidman JG, Seidman CE, Rosenthal N, Fatkin D and Harvey RP: Functional characterization of a novel mutation in NKX2-5 associated with congenital heart disease and adult-onset cardiomyopathy. Circ Cardiovasc Genet 6: 238-247, 2013

45. Kirk EP, Sunde M, Costa MW, Rankin SA, Wolstein O, Castro ML, Butler TL, Hyun C, Guo G, Otway R, Mackay JP Waddell LB, Cole AD, Hayward C, Keogh A, Macdonald P, Griffiths L, Fatkin D, Sholler GF, Zorn AM, Feneley MP, Winlaw DS and Harvey RP: Mutations in cardiac T-box factor gene TBX20 are associated with diverse cardiac pathologies, including defects of septation and valvulogenesis and cardiomyopathy. Am J Hum Genet 81: 280-291, 2007.

46. Yang YQ, Wang J, Wang XH, Wang Q, Tan HW, Zhang M, Shen FF, Jiang JQ, Fang WY and Liu X: Mutational spectrum of the GATA5 gene associated with familial atrial fibrillation. Int J Cardiol 157: 305-307, 2012.

47. Gu JY, Xu JH, Yu H and Yang YQ: Novel GATA5 loss-of-function mutations underlie familial atrial fibrillation. Clinics (Sao Paulo) 67: 1393-1399, 2012.

48. Wang XH, Huang CX, Wang Q, Li RG, Xu YJ, Liu X, Fang WY and Yang YQ: A novel GATA5 loss-of-function mutation underlies lone atrial fibrillation. Int J Mol Med 31: 43-50, 2013.

49. Huang RT, Xue S, Xu YJ, Zhou M and Yang YQ: A novel NKX2.5 loss-of-function mutation responsible for familial atrial fibrillation. Int J Mol Med 31: 1119-1126, 2013.

50. Xie WH, Chang C, Xu YJ, Li RG, Qu XK, Fang WY, Liu X and Yang YQ: Prevalence and spectrum of Nkx2.5 mutations associated with idiopathic atrial fibrillation. Clinics (Sao Paulo) 68: 777-784, 2013.

51. Yang YQ, Xu YJ,Li RG, Qu XK, Fang WY and Liu X: Prevalence and spectrum of PITX2c mutations associated with familial atrial fibrillation. Int J Cardiol 168: 2873-2876, 2013.

52. Zhou YM, Zheng PX, Yang YQ, Ge ZM and Kang WQ: A novel PITX2c loss-of-function mutation underlies lone atrial fibrillation. Int J Mol Med 32: 827-834, 2013.

53. Wang J, Zhang DF, Sun YM and Yang YQ: A novel PITX2c loss-of-function mutation associated with familial atrial fibrillation. Eur J Med Genet 57: 25-31, 2014. 